\title{
A Novel Decision Making Based on Interval Valued Intuitionistic Fuzzy Soft Set
}

\author{
Lishi Zhang \\ School of Science \\ Dalian Ocean University \\ Dalian, China \\ e-mail:dwtag@sohu.com
}

\begin{abstract}
Molodtsov first proposed the soft set theory, which can be used as a general mathematical tool for dealing with fuzzy and uncertain information. As a generalization of soft set, interval-valued intuitionistic fuzzy soft set is another soft set structure, it is a combination of an interval-valued intuitionistic fuzzy set and a soft set. The objective of this paper is to study the decision making based on intervalvalued intuitionistic fuzzy soft sets, the optimcal choice is needed to choose the best performance of the objects, in [1]Zhang introduces the level soft sets, it can get the choice value of objects, in the present paper, we introduce the distance to evaluate the objects, the numberical example shows that the criteria is reasonable in objects selection on interval-valued intuitionistic fuzzy soft set.
\end{abstract}

Keywords-component; soft set; interval-valued intuitionistic fuzzy soft set; attribute;incomplete information; choice value.

\section{INTRODUCTION}

The soft set theory, originally proposed by Molodtsov [2], can be deemed as a general mathematical tool to deal with uncertainty, imprecision and fuzziness in information system[3]. Soft set theory has been successfully applied in many fields such as data analysis, functions smoothness, forecasting, game theory, theory of measurement and so on. In recent years, soft set theory has attracted considerable attention [4-8]. By integrating soft set theory with other classical mathematical models, a lot of extensions of soft set model have also been made[9-11], this includes fuzzy soft sets, generalized fuzzy soft sets [12], interval-valued fuzzy soft sets, vague soft sets[13], and intuitionistic fuzzy soft sets. At the same time, some approaches of decision making to these extended fuzzy soft sets have also been developed. Level soft sets was first introduced by Feng et al. [14] to present an adjustable approach to fuzzy soft set based decision making. Jiang et al. [15]generalized the adjustable approach to fuzzy soft sets based decision making by converting the data into a classical soft set, provided an adjustable approach to intuitionistic fuzzy soft sets based decision making.

As a generalization of Zadeh's fuzzy sets, Zadeh's interval-valued fuzzy sets and Atanassov's intuitionistic fuzzy sets, the concept of an interval-valued intuitionistic fuzzy set was proposed for the first time by Atanassov and Gargov. Compared to fuzzy sets, interval-valued fuzzy sets and intuitionistic fuzzy sets, an interval-valued intuitionistic fuzzy set has a membership degree and a non-membership degree to which an element belongs to a set, and both membership degree and non-membership degree are denoted by interval numbers of the unit interval $[0,1]$. Hence, it is more flexible and effective for intervalvalued intuitionistic fuzzy sets to deal with imperfect and imprecise information. By introducing the interval-valued intuitionistic fuzzy sets into soft sets, Jiang et al. [16]defined a concept of interval-valued intuitionistic fuzzy soft set and defined some operations on the interval-valued intuitionistic fuzzy soft sets and investigated some basic properties. In paper [1], Zhang investigated the decision making based on interval-valued intuitionistic fuzzy soft sets. An adjustable approach was presented to interval-valued intuitionistic fuzzy soft sets based decision making by mean of level soft sets of intervalued intuitionistic fuzzy soft sets, the threshold was the medium value, the value is imposed in advance with less regard to the raw data itself. The aim of the present paper is to get the choice value with the distance function, the choice value is directly derived from the data, no human intervene is involved, the novelty of the present paper is that it uses the distance function which can different objects efficiently, and every process is manipulated only by raw data.

The rest of this paper is arranged as follows. Section 2 briefly recalls some background knowledge. Section 3 introduces the distance function which can measure the distance between two objects. Section 4 gives an illustrative example to verify our methods. Finally, Section 5 ends this paper with some concluding remarks.

\section{PRELIMINARIES}

In the present section we will briefly recall some basic 
definitions and background knowledge of intuitionistic fuzzy soft sets

Definition 2.1.[1]The mapping $\boldsymbol{t}^{\boldsymbol{t}}: U \rightarrow L$ is called an interval-valued intuitionistic fuzzy set on $U$. The intervalvalued intuitionistic fuzzy set can also be denoted by

$$
\begin{aligned}
& \mathbf{H}^{\boldsymbol{t}}=\left\{\left\langle x, \mu_{\mu}(x), v_{\mu}(x)\right\rangle \mid x \in U\right\} \\
& =\left\{\left\langle x,\left[\mu_{\mathbb{X}_{L}}(x), \mu_{\mathbb{X}_{R}}(x)\right],\left[v_{\mathbb{X}_{L}}(x), v_{\mathbb{X}_{R}}(x)\right]\right\rangle \mid x \in U\right\}
\end{aligned}
$$

Where

$$
\mu_{\mu^{t}}(x)=\left[\mu_{\mathbb{X}_{L}}(x), \mu_{\mathscr{X}_{R}}(x)\right] \text { and } \mu_{\mu^{u}}(x)=\left[\mu_{\mathscr{X}_{L}}(x), \mu_{\mathscr{X}_{R}}(x)\right]
$$

satisfy $0 \leq \mu_{\mathfrak{X}_{R}}(x)+v_{\mathfrak{X}_{R}}(x) \leq 1$ for all $x \in U$, and are,

respectively, called the degree of membership and the degree of non-membership of the element $x \in U$. Let $\operatorname{LVIF}(U)$ denote the family of all interval-valued intuitionistic fuzzy sets on $U$.

Example 2.1. Let the universe $U=\left\{x_{1}, x_{2}, x_{3}\right\}$ and

$$
\begin{aligned}
\mathbf{t} & =\left\{\left\langle x_{1},[0.35,0.6],[0.2,0.35]\right\rangle,\right. \\
& \left.=\left\langle x_{2},[0.2,0.3],[0.5,0.65]\right\rangle,\left\langle x_{3},[0.8,0.9],[0.05,0.07]\right\rangle\right\}
\end{aligned}
$$

Then, by Definition 2.1 , it is easy to see that is an interval-valued intuitionistic fuzzy set on $U$.

By combining the concept of interval-valued intuitionistic fuzzy sets with the theory of soft sets, jiang et al. [16] put forward the concept of the interval-valued intuitionistic fuzzy soft sets as follows.

Definition 2.2 [16]. Let $U$ be an initial universe and $A \subseteq E$ be a set of parameters, a pair $(\stackrel{\circ}{F}, A)$ is called an interval-valued intuitionistic fuzzy soft set over $U$, where $\stackrel{\circ}{F}$ is a mapping given by $\stackrel{\circ}{F}: A \rightarrow \operatorname{LVIF}(U)$.

In the above definition, interval-valued intuitionistic fuzzy subsets in the universe $U$ are replaced as the crisp subsets of $U$, the following example will illustrate the concept.

Example 2.2[1].Let universe $U=\left\{h_{1}, h_{2}, h_{3}, h_{4}, h_{5}, h_{6}\right\}$ be a set of houses, $A=\left\{e_{1}, e_{2}, e_{3}, e_{4}, e_{5}\right\}$ be a set of parameters $e_{1}$ stands for "expensive", $e_{2}$ stands for "beautiful", $e_{3}$ stands for "wooden", $e_{4}$ stands for "in green surroundings", $e_{5}$ stands for "convenient traffic". Suppose that Mr. $X$ wants to buy the house which qualifies with the attributes in $A$ to the utmost exten.which one would he select?

Intuitionistic fuzzy set is characterized by a membership function and a nonmembership function, and thus can describe the fuzzy character of data more delaborately than Zadeh's fuzzy set which is characterized only by a membership function. For example, the characteristics of the house $h_{1}$ under the parameter $e_{1}$ is $(0.7,0.1)$. The values of 0.7 and 0.1 are the degrees of membership and non-membership of the house $h_{1}$ with the parameter $e_{1}$, respectively. That is, house $h_{1}$ is expensive on the membership degree of 0.7 and it is not expensive on the non-membership degree of 0.1 . In many cases, it is hard to choose the crisp membership degrees and nonmembership degrees of elements in an intuitionistic fuzzy set. Therefore, it is more rational to represent as an degree of membership interval-valued and an interval-valued degree of non-membership to each element of the universe. Thus, the characteristics of the six houses with respect to the five parameters are represented by the interval-valued intuitionistic fuzzy sets $(\stackrel{\circ}{F}, A)$ as follows.

\begin{tabular}{|c|c|c|c|}
\hline$U$ & $e_{1}$ & $e_{2}$ & $e_{3}$ \\
\hline$h_{1}$ & {$[0.7,0.8][0.1,0.2]$} & {$[0.6,0.7][0.2,0.3]$} & {$[0.1,0.2][0.5,0.7]$} \\
\hline$h_{2}$ & {$[0.2,0.3][0.5,0.6]$} & {$[0.6,0.8][0.1,0.1]$} & {$[0.3,0.4][0.4,0.5]$} \\
\hline$h_{3}$ & {$[0.3,0.6][0.2,0.3]$} & {$[0.2,0.3][0.4,0.6]$} & {$[0.4,0.6][0.2,0.4]$} \\
\hline$h_{4}$ & {$[0.2,0.3][0.5,0.6]$} & {$[0.1,0.1][0.7,0.8]$} & {$[0.2,0.3][0.6,0.6]$} \\
\hline$h_{5}$ & {$[0.8,0.9][0.0,0.1]$} & {$[0.2,0.5][0.3,0.4]$} & {$[0.1,0.4][0.2,0.5]$} \\
\hline$h_{6}$ & {$[0.0,0.1][0.6,0.7]$} & {$[0.9,1.0][0.0,0.0]$} & {$[0.7,0.8][0.1,0.1]$} \\
\hline$U$ & $e_{4}$ & $e_{5}$ & \\
\hline$h_{1}$ & {$[0.4,0.6][0.0,0.1]$} & {$[0.2,0.3][0.5,0.6]$} & \\
\hline$h_{2}$ & {$[0.3,0.4][0.5,0.5]$} & {$[0.1,0.8][0.0,0.1]$} & \\
\hline$h_{3}$ & {$[0.2,0.3][0.6,0.6]$} & {$[0.3,0.5][0.4,0.5]$} & \\
\hline$h_{4}$ & {$[0.5,0.6][0.2,0.3]$} & {$[0.5,0.5][0.3,0.4]$} & \\
\hline$h_{5}$ & {$[0.3,0.3][0.4,0.4]$} & {$[0.3,0.4][0.1,0.3]$} & \\
\hline$h_{6}$ & {$[0.6,0.7][0.2,0.3]$} & {$[0.2,0.3][0.4,0.7]$} & \\
\hline
\end{tabular}

$$
\begin{aligned}
\stackrel{\circ}{F}\left(e_{1}\right)= & \left\{\left\langle h_{1},[0.7,0.8],[0.1,0.2]\right\rangle,\left\langle h_{2},[0.2,0.3],[0.5,0.6]\right\rangle,\right. \\
& \left\langle h_{3},[0.3,0.6],[0.2,0.3]\right\rangle,\left\langle h_{4},[0.2,0.3],[0.5,0.6]\right\rangle, \\
& \left.\left\langle h_{5},[0.8,0.9],[0.0,0.1]\right\rangle,\left\langle h_{6},[0.0,0.1],[0.6,0.7]\right\rangle\right\} . \\
\stackrel{\circ}{F}\left(e_{2}\right)= & \left\langle\left\langle h_{1},[0.6,0.7],[0.2,0.3]\right\rangle,\left\langle h_{2},[0.6,0.8],[0.1,0.1]\right\rangle,\right. \\
& \left\langle h_{3},[0.2,0.3],[0.4,0.6]\right\rangle,\left\langle h_{4},[0.1,0.1],[0.7,0.8]\right\rangle, \\
& \left.\left\langle h_{5},[0.2,0.5],[0.3,0.4]\right\rangle,\left\langle h_{6},[0.9,1.0],[0.0,0.0]\right\rangle\right\} . \\
\stackrel{\circ}{F}\left(e_{3}\right)= & \left\langle\left\langle h_{1},[0.1,0.2],[0.5,0.7]\right\rangle,\left\langle h_{2},[0.3,0.4],[0.4,0.5]\right\rangle,\right. \\
& \left\langle h_{3},[0.4,0.6],[0.2,0.4]\right\rangle,\left\langle h_{4},[0.2,0.3],[0.6,0.6]\right\rangle, \\
& \left.\left\langle h_{5},[0.1,0.4],[0.2,0.5]\right\rangle,\left\langle h_{6},[0.7,0.8],[0.1,0.1]\right\rangle\right\} . \\
\stackrel{\circ}{F}\left(e_{4}\right)= & \left\{\left\langle h_{1},[0.4,0.6],[0.0,0.1]\right\rangle,\left\langle h_{2},[0.3,0.4],[0.5,0.5]\right\rangle,\right. \\
& \left\langle h_{3},[0.2,0.3],[0.6,0.6]\right\rangle,\left\langle h_{4},[0.5,0.6],[0.2,0.3]\right\rangle, \\
& \left.\left\langle h_{5},[0.3,0.3],[0.4,0.4]\right\rangle,\left\langle h_{6},[0.6,0.7],[0.2,0.3]\right\rangle\right\} . \\
\stackrel{\circ}{F}\left(e_{5}\right)= & \left\{\left\langle h_{1},[0.2,0.3],[0.5,0.6]\right\rangle,\left\langle h_{2},[0.1,0.8],[0.0,0.1]\right\rangle,\right. \\
& \left\langle h_{3},[0.3,0.5],[0.4,0.5]\right\rangle,\left\langle h_{4},[0.5,0.5],[0.3,0.4]\right\rangle, \\
& \left.\left\langle h_{5},[0.3,0.4],[0.1,0.3]\right\rangle,\left\langle h_{6},[0.2,0.3],[0.4,0.7]\right\rangle\right\} .
\end{aligned}
$$

The interval-valued intuitionistic fuzzy sets $(\stackrel{\circ}{F}, A)$ is put as follows

TABle I. The Tabular Representation of $(\stackrel{\circ}{F}, A)$

\section{PROPOSED APPROACH}

The entries of the objects are all " 1 " in the table, but all the importance of attributes are not equal, for a given data set, the weights of attributes are not always given in advance, it is reasonable to derive them from the concrete dataset, in the present paper, we first derive the weights from the data by Kong's method, then we transform the dataset with the weights, then again with Kong's method, we get the final choice value.

Suppose $U=\left\{h_{1}, h_{2}, \ldots \ldots, h_{\mathrm{n}}\right\}, E=\left\{e_{1}, e_{2}, \ldots \ldots, e_{\mathrm{m}}\right\}$, $(F, E)$ is a soft set with tabular representation.

Define

$$
f_{E}\left(h_{i}\right)=\sum_{j}\left\{h_{i j}\right\}
$$


As the choice value, where $h_{\mathrm{ij}}$ are the entries in soft set table.

TABLE II. THE TABULAR REPRESENTATION OF $\{F, E\}$

\begin{tabular}{|l|l|l|l|l|}
\hline$U$ & $e_{1}$ & $e_{2}$ & $e_{3}$ & $e_{4}$ \\
\hline$h_{1}$ & 1 & 1 & 1 & 0 \\
\hline$h_{2}$ & 0 & 1 & 0 & 1 \\
\hline$h_{3}$ & 1 & 0 & 1 & 1 \\
\hline$h_{4}$ & 1 & 0 & 0 & 1 \\
\hline
\end{tabular}

In the above table, the choice values are computed as

$$
f_{E}\left(h_{1}\right)=3 ; f_{E}\left(h_{2}\right)=2 ; f_{E}\left(h_{3}\right)=3 ; f_{E}\left(h_{4}\right)=2
$$

In the present paper, we used the distance function to evaluate the choice values.

Let $U=\left\{x_{1}, x_{2}, \mathrm{~L} \mathrm{~L}, x_{n}\right\}$ be an initial universe and $E=\left\{e_{1}, e_{2}, \mathrm{~L} \mathrm{~L}, e_{m}\right\}$ be a set of parameters, $(\stackrel{\circ}{F}, A)$ is an interval-valued intuitionistic fuzzy soft set over $U$, and its matrix form is

$$
\left(\begin{array}{cccc}
\alpha_{11} & \alpha_{12} & \mathrm{~L} & \alpha_{1 m} \\
\alpha_{21} & \alpha_{22} & \mathrm{~L} & \alpha_{2 m} \\
\mathrm{M} & \mathrm{M} & \mathrm{M} & \mathrm{M} \\
\alpha_{n 1} & \alpha_{n 2} & \mathrm{~L} & \alpha_{n m}
\end{array}\right)
$$

Where $\stackrel{\circ}{F}\left(e_{j}\right)=\left\{\alpha_{1 j}, \alpha_{2 j}, \mathrm{~L} \mathrm{~L}, \alpha_{n j}\right\}, j=1,2, \mathrm{~L} \mathrm{~L}, m$.

$$
\alpha_{i j}=\left\{\left[\mu_{j}^{L}\left(x_{i}\right), \mu_{j}^{R}\left(x_{i}\right)\right],\left[v_{j}^{L}\left(x_{i}\right), v_{j}^{R}\left(x_{i}\right)\right]\right\}, i=1,2, \mathrm{~L} \mathrm{~L}, n .
$$

$\mathrm{Xu}$ [17] defined the distance between $\alpha_{i j}$ and $\alpha_{i k}$ as

$$
\begin{aligned}
d\left(\alpha_{i j}, \alpha_{k j}\right)= & \frac{1}{4}\left(\left|\mu_{j}^{L}\left(x_{i}\right)-\mu_{j}^{L}\left(x_{k}\right)\right|+\left|\mu_{j}^{R}\left(x_{i}\right)-\mu_{j}^{R}\left(x_{k}\right)\right|\right. \\
& \left.+\left|v_{j}^{L}\left(x_{i}\right)-v_{j}^{L}\left(x_{k}\right)\right|+\left|v_{j}^{R}\left(x_{i}\right)-v_{j}^{R}\left(x_{k}\right)\right|\right)
\end{aligned}
$$

The distance between $h_{i}$ and $h_{k}$ is

$$
D\left(h_{i}, h_{k}\right)=\sum_{j=1}^{m} d\left(\alpha_{i j}, \alpha_{k j}\right)
$$

The function has the following properties;

(1) $0 \leq D\left(h_{i}, h_{k}\right) \leq 1$; especially $D\left(h_{i}, h_{i}\right)=0$;

(2) $D\left(h_{i}, h_{k}\right)=D\left(h_{k}, h_{i}\right)$;

(3) $D\left(h_{i}, h_{k}\right) \leq D\left(h_{i}, h_{j}\right)+D\left(h_{j}, h_{k}\right)$;

The distance are used to differentiate the alternatives, furthermore, $\mathrm{Xu}[17]$ introduced the deviation between one alternatives with respect to all the other attributes, as we know that if one object is special and can

Differentiate itself from all the other objects, then the corresponding deviation ought to be the largest, based on this perspective, we define the derivation as the score function, that is, the choice value.

$$
S\left(h_{i}\right)=\sum_{j=1}^{n} D\left(h_{i}, h_{j}\right)
$$

is the choice value of objects $h_{i}$.

\section{SIMULATION}

Now we consider the choice value of objects in Example 2.2 , the distance of objects are listed in matrix $D$, the deviation is computed as,

$$
\begin{aligned}
& S\left(h_{1}\right)=\sum_{j=1}^{6} D\left(h_{1}, h_{j}\right)=(0+5.7+5.5+5.7+3.9+6.6) / 4=6.85 \\
& S\left(h_{2}\right)=\sum_{j=1}^{6} D\left(h_{2}, h_{j}\right)=(5.7+0+5.0+5.2+5.0+5.5) / 4=6.6 \\
& D=(D(i, j))_{6 \times 6}=\frac{1}{4}\left(\begin{array}{cccccc}
0 & 5.7 & 5.5 & 5.7 & 3.9 & 6.6 \\
5.7 & 0 & 5.0 & 5.2 & 5.0 & 5.5 \\
5.5 & 5.0 & 0 & 4.6 & 3.4 & 6.9 \\
5.7 & 5.2 & 4.6 & 0 & 5.6 & 6.9 \\
3.9 & 5.0 & 3.4 & 5.6 & 0 & 8.1 \\
6.6 & 5.5 & 6.9 & 6.9 & 8.1 & 0
\end{array}\right) \\
& S\left(h_{3}\right)=\sum_{j=1}^{6} D\left(h_{3}, h_{j}\right)=(5.5+5.0+0+4.6+3.4+6.9) / 4=6.35 \\
& S\left(h_{4}\right)=\sum_{j=1}^{6} D\left(h_{4}, h_{j}\right)=(5.7+5.2+4.6+0+5.6+6.9) / 4=7 \\
& S\left(h_{5}\right)=\sum_{j=1}^{6} D\left(h_{5}, h_{j}\right)=(3.9+5.0+3.4+5.6+0+8.1) / 4=6.5 \\
& S\left(h_{6}\right)=\sum_{j=1}^{6} D\left(h_{6}, h_{j}\right)=(6.6+5.5+6.9+6.9+8.1+0) / 4=8.5
\end{aligned}
$$

The order of the choice value is

$$
S\left(h_{6}\right)>S\left(h_{4}\right)>S\left(h_{1}\right)>S\left(h_{2}\right)>S\left(h_{5}\right)>S\left(h_{3}\right)
$$

Thus, $h_{6}$ is the optimal choice object, $h_{4}$ is the suboptimal choice object. According to [1], with the level set

\begin{tabular}{|c|c|c|}
\hline$U$ & $e_{1}$ & $e_{2}$ \\
\hline$h_{1}$ & {$[0.114,0.130][0.016,0.033]$} & {$[0.098,0.114][0.033,0.049]$} \\
\hline$h_{2}$ & {$[0.032,0.048][0.080,0.096]$} & {$[0.096,0.128][0.016,0.016]$} \\
\hline$h_{3}$ & {$[0.043,0.088][0.029,0.044]$} & {$[0.029,0.044][0.059,0.088]$} \\
\hline$h_{4}$ & {$[0.035,0.052][0.086,0.103]$} & {$[0.017,0.017][0.121,0.138]$} \\
\hline$h_{5}$ & {$[0.125,0.141][0.000,0.016]$} & {$[0.031,0.078][0.047,0.063]$} \\
\hline$h_{6}$ & {$[0.000,0.020][0.122,0.142]$} & {$[0.182,0.203][0.000,0.000]$} \\
\hline$U$ & $e_{3}$ & $e_{4}$ \\
\hline$h_{1}$ & {$[0.016,0.033][0.081,0.114]$} & {$[0.065,0.098][0.000,0.016]$} \\
\hline$h_{2}$ & {$[0.048,0.064][0.064,0.080]$} & {$[0.048,0.064][0.080,0.080]$} \\
\hline$h_{3}$ & {$[0.059,0.088][0.029,0.059]$} & {$[0.029,0.044][0.088,0.088]$} \\
\hline$h_{4}$ & {$[0.035,0.052][0.103,0.103]$} & {$[0.086,0.103][0.035,0.052]$} \\
\hline$h_{5}$ & {$[0.016,0.063][0.031,0.078]$} & {$[0.047,0.047][0.063,0.063]$} \\
\hline$h_{6}$ & {$[0.142,0.162][0.020,0.020]$} & {$[0.122,0.142][0.041,0.061]$} \\
\hline$U$ & $e_{5}$ & \\
\hline$h_{1}$ & {$[0.033,0.049][0.082,0.098]$} & \\
\hline$h_{2}$ & {$[0.016,0.128][0.000,0.016]$} & \\
\hline$h_{3}$ & {$[0.044,0.073][0.059,0.073]$} & \\
\hline$h_{4}$ & {$[0.086,0.086][0.052,0.069]$} & \\
\hline$h_{5}$ & {$[0.047,0.063][0.016,0.047]$} & \\
\hline$h_{6}$ & {$[0.041,0.061][0.081,0.142]$} & \\
\hline
\end{tabular}
approach, Zhang got the maximal optimal choice value is $h_{6}=\max _{1 \leq i \leq 6} h_{i}$, it coincides with our proposed approach.

Many distance functions can be used to define the choice value, for instance, when we replace the above function with the Euclidean distance, then the order of the choice value is

$$
S\left(h_{6}\right)>S\left(h_{4}\right)>S\left(h_{1}\right)>S\left(h_{3}\right)>S\left(h_{2}\right)>S\left(h_{5}\right) .
$$

$h_{6}=\max _{1 \leq i \leq 6} h_{i}$, then, $h_{6}$ is also the optimal choice object, $h_{4}$ is the suboptimal choice object.

Now we use the deviation as the weights of objects, the, by implenting the OWA operators[17], we get the Score functions, we follow the steps as follows

1. Transform the data with the deviations of objects

TABle III. The Tabular Representation of $(\stackrel{\circ}{F}, A)$ 
2. Let weights $\mathrm{w}=[0.2,0.2,0.2,0.2,0.2]$,by the IIFWA operator(Interval-valued Intuitionistic Fuzzy Weights Average Aggreator).

$\operatorname{IIFWA_{\omega }}\left(\alpha_{11}, \alpha_{12}, \alpha_{13}, \alpha_{14}, \alpha_{15}\right)=([0.0658,0.0854],[0.0000,0.0492])$

IIFWA $A_{\omega}\left(\alpha_{21}, \alpha_{22}, \alpha_{23}, \alpha_{24}, \alpha_{25}\right)=([0.0483,0.0870],[0.0000,0.0435])$

IIFWA $A_{\omega}\left(\alpha_{31}, \alpha_{32}, \alpha_{33}, \alpha_{34}, \alpha_{35}\right)=([0.0411,0.0676],[0.0481,0.0680])$

IIFWA $A_{\omega}\left(\alpha_{41}, \alpha_{42}, \alpha_{43}, \alpha_{44}, \alpha_{45}\right)=([0.0521,0.0625],[0.0718,0.0879])$

IIFWA $A_{\omega}\left(\alpha_{51}, \alpha_{52}, \alpha_{53}, \alpha_{54}, \alpha_{55}\right)=([0.0539,0.0787],[0.0000,0.0467])$

IIFWA $A_{\omega}\left(\alpha_{61}, \alpha_{62}, \alpha_{63}, \alpha_{64}, \alpha_{65}\right)=([0.0997,0.1201],[0.0000,0.0000])$

The scores are computed as

$$
\begin{aligned}
& S\left(h_{1}\right)=\frac{1}{2}(0.0658+0.0854-0.0000-0.0492)=-0.0225 \\
& S\left(h_{2}\right)=\frac{1}{2}(0.0483+0.0870-0.0000-0.0435)=-0.0038 \\
& S\left(h_{3}\right)=\frac{1}{2}(0.0411+0.0676-0.0481-0.0680)=0.0429 \\
& S\left(h_{4}\right)=\frac{1}{2}(0.0521+0.0625-0.0718-0.0879)=0.0459 \\
& S\left(h_{5}\right)=\frac{1}{2}(0.0539+0.0787-0.0000-0.0467)=0.0510 \\
& S\left(h_{6}\right)=\frac{1}{2}(0.0997+0.1201-0.0000-0.0000)=0.1099
\end{aligned}
$$

Then the order of the score is

$$
S\left(h_{6}\right)>S\left(h_{1}\right)>S\left(h_{2}\right)>S\left(h_{5}\right)>S\left(h_{3}\right)>S\left(h_{4}\right) .
$$

$h_{6}=\max _{1 \leq i \leq 6} h_{i}$, then, $h_{6}$ is also the optimal choice object, $h_{1}$ is the suboptimal choice object.

\section{CONCLUSION}

In this paper, we propose a distance based approach which acts as the choice values in decision making in interval-valued intuitionistic fuzzy sets, in the practical example, we know that the proposed approach is feasible and effective. The future effort ought to exert on the investigation in other decision making fields such as fuzzy soft set theory, vague set theory and other fuzzy objects theory.

\section{REFERENCES}

[1] Z. Zhang, C. Wang and D. Z.Tian. "A novel approach to intervalvalued intuitionistic fuzzy soft set based decision making," Appl. Math. Model,Vol 38, 2014, pp.1255-1270.

[2] D. Molodtsov. "Soft set theory-first results," Comput. Math. Appl, Vol 37, 1999, pp.19-31.

[3] L.A. Zadeh. "Fuzzy Sets, ” Inf. Control, Vol 8, 1965,pp.338-353.

[4] M.I. Ali, F. Feng and S. Liu. "On some new operations in soft set theory," Comput. Math. Appl. Vol 57, 2009,pp.1547-1553.

[5] N. Cag man, S. Enginog lu."Soft set theory and uni-int decision making, ” Eur. J. Oper. Res. Vol 207,2010, pp.848-855.

[6] K. Gong, P.P. Wang and Z. Xiao."Bijective soft set decision system based parameters reduction under fuzzy environments," Appl. Math. Model. Vol 37, 2013, pp.4474-4485.

[7] Z. Kong, L. Gao and L.F. Wang. "The normal parameter of soft sets and its algorithm," Comput. Math. Appl. Vol 56, 2008 , pp.3029-3037.

[8] Y. Zou, Z. Xiao. "Data analysis approaches of soft sets under incomplete information," Knowl.-Based Syst, Vol 21, No 8, 2008, pp.941-945.

[9] T.Q. Deng, X.F. Wang.“An object-parameter approach to predicting unknown data in incomplete fuzzy soft sets," Appl. Math. Model,Vol 37,No 6, 2013, pp.4139-4146.

[10] T.M. Basu, N.K. Mahapatra and S.K. "Mondal, A balanced solution of a fuzzy soft set based decision making problem in medical science," Appl. Soft Comput, Vol 12,No 10, 2012 , pp.3260-3275.

[11] Z.M. Zhang. "A rough set approach to intuitionistic fuzzy soft set based decision making," Appl. Math. Model, Vol 36, 2012 , pp4605-4633.

[12] P. Majumdar, S.K. Samanta. "Generalised fuzzy soft sets, " Comput. Math. Appl, Vol 59, 2010, pp.1425-1432.

[13] W. Xu, J. Ma and S.Y. Wang. "Vague soft sets and their properties," Comput.Math.Appl,Vol59,2010,pp.787-794.

[14] F. Feng, Y.B. Jun and X.Y. Liu. "An adjustable approach to fuzzy soft set based decision making," J. Comput. Appl. Math.,Vol 234,2010, pp.10-20.

[15] Y. Jiang, Y. Tang and Q. Chen."An adjustable approach to intuitionistic fuzzy soft sets based decision making," Appl. Math. Model, Vol 35, 2011, pp.824-836.

[16] Y. Jiang, Y. Tang and Q. Chen."Interval-valued intuitionistic fuzzy soft sets and their properties," Comput. Math. Appl,Vol 60, 2010 , pp.906-918.

[17] Z.S.Xu."A deviation-based approach to Interval-valued intuitionistic fuzzy multiple attribute group decision making," Group Decision and Negotiation, Vol 19, 2010, pp.57-76. 